\title{
Complementation markers in Early Modern Greek: A corpus-based approach
}

\author{
Eleni Karantzola \\ University of the Aegean \\ karantzola@rhodes.aegean.gr
}

\author{
Konstantinos Sampanis \\ University of the Aegean \\ k. sampanis@rhodes. aegean.gr
}

\begin{abstract}
The article focuses on the investigation of the function and distribution of certain complementation markers in Early Modern Greek. The quantitative analysis of these phenomena can indicate patterns of complement markers usage which are determined by factors such as dialectic or stylistic variation. Moreover, it is emphasized that thorough investigation within a larger corpus is decisive for the study of morphosyntactic change since this reveals minor cases of phenomena which may otherwise remain unnoticed, although they may be important to better comprehend how structures emerge, get established or become obsolete in the diachrony of a given language.
\end{abstract}

\section{Introduction}

Digging through corpora of older or contemporary texts is the most viable way for us linguists to understand language change. In fact, this occurs due to variation, which in turn leads to what Kroch (1989) calls "Grammars in Competition", a state in which two systems of structures antagonistically co-exist until one replaces another entirely, as the usual course of language change is.

Corpus Linguistics is the indispensable method for observing variation. The term of variability applies either to genuinely linguistic features such as frequency and distribution of lexical types or morphosyntactic structures or to sociolinguistic factors such as registers or dialects and of course time (cf. Biber et al., 1998: 6).

In our research we present three cases regarding the usage of Complement Markers (CMs) in Early Modern Greek (EMG, $16^{\text {th }}-17^{\text {th }}$ c.). Two of these cases, the occurrence of "pleonastic" CMs (3.1.) and the configuration of the converb of the copula verb plus complementation marker (3.2.) are structures that differentiate EMG from Standard Modern Greek (SMG). In the third case (3.3.), we trace the first indications for the rise of the Modern Greek (MG) factive complement marker (CM) $\pi$ ov $p u$. In all three cases, the corpus-based approach enabled us to gain better insight into the linguistic and non-linguistic factors that determine the distribution of these structures. As it will be discussed, the study of the EMG Corpus was a necessity not only for understanding these syntactic cases but even for getting aware of these phenomena which have been passed largely unnoticed up to now.

\subsection{Towards an Early Modern Greek Corpus}

Given its uninterrupted and continuous documentation from the $15^{\text {th }}$ c. B.C. to nowadays, the importance of Greek in diachronic linguistics is paramount (cf. Horrocks ${ }^{2} 2010$ and Tonnet ${ }^{3} 2011$ for thorough introductions to the history of the language). Due to the long tradition, philologists and linguists have been working on examining the different linguistic eras of the language. Still, the period immediately after the end of the "Medieval" linguistic phase (conventionally marked by the date of the Fall of Constantinople in 1453) and until the $18^{\text {th }} \mathrm{c}$. has been linguistically poorly investigated. Thus, despite the emergence of numerous texts in 
the vernacular, there has been a gap in the exact reconstruction of how Medieval Greek led to SMG or the various Modern Greek dialects.

The compilation then of an EMG Corpus was a desideratum that, to a certain extent, has been satisfied by recent publications or unpublished dissertations. Thanks to the work that has been done at the Laboratory of Linguistics of Southern-Eastern Mediterranean (Department of Mediterranean Studies, University of the Aegean), a large collection of transcribed manuscripts or older editions has been brought together and digitized. This is now for the first time available for linguistic research. Additionally, the Corpus is being steadily expanded through the addition of new texts. Out of this textual depository, in our corpus-based approach, we dealt with the following works:

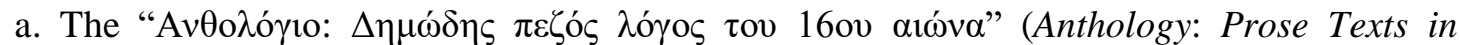
Vernacular Greek of the 16th century, cf. Kakoulidi-Panou, Karantzola \& Tiktopoulou, in press): 250 textual excerpts (c. 550 pages). This is a collection of texts of various genres and registers gleaned from different regions of the Greek-speaking world of that period (especially Crete, Ionian Islands, Constantinople and Greek mainland), featuring dialectical traces. Due to its representativeness, "Anthology" provides a unique overview of the written production, and consequently the linguistic situation, of that era.

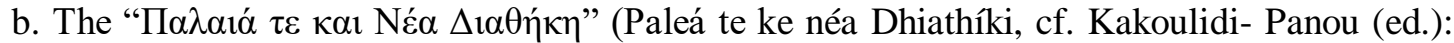
2000) of the Corfiot Ioannikios Kartanos (Venice 1536, c. 145,000 words), the first rendition of excerpts of the Bible in vernacular Greek, which was composed a century before the "official" translation of Maximos Kallipolitis (1638).

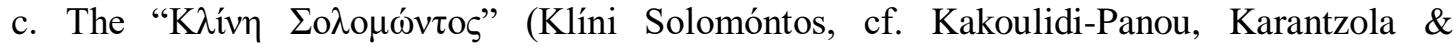
Chalvatzidaki, (eds.). 2007) of the Cretan Ioannis Morezinos (1598, c. 82,000 words), a narration of sixty miracles of the Virgin Mary, with Cretan dialectical features (ms Xiropotamou, 1602).

d. The unpublished dissertation composed by An. Papaioannou (2016): Prose texts in vernacular Greek, of writers of the 16th and 17th c., according to autograph manuscripts [in Greek]. University of the Aegean, Rhodes.

The annotation of texts and a detailed description of this linguistic period in the light of the Corpus will be the next steps in our research.

\section{SMG complementation and EMG complement markers}

One of the major characteristics that differentiate most varieties of MG from older stages of the language is the overall absence of non-finite complementation structures ${ }^{1}$, a phenomenon that has been systematically discussed in Joseph (1983). Hence, with the exception of certain control structures in Pontic Greek ${ }^{2}$ and the Southern Italian Greek dialects ${ }^{3}$, SMG and most MG dialects make use of a system of dependent complement clauses introduced by CMs that are followed by a finite verbal form. The loss of the infinitive was gradual, but it was undoubtedly complete during the period we examine (cf. also Horrocks ${ }^{2} 2010$ : 296f). Actually, the recession of the infinitive can be observed many centuries before the EMG period. For example, in an excerpt of Leimón (Spiritual Meadow) composed by Ioannes Moschos (c.550 - 619), the complement

\footnotetext{
${ }^{1}$ In MG there are two non-finite verbal forms, a converb (in the sense of Haspelmath 1995, also often called a "gerund", cf. e.g. Holton et al. ${ }^{2} 2012:$ 306f.) and an infinitive-like component of the analytic perfect tenses that is marked with perfective aspect, e.g. $\mu \imath \lambda \eta \dot{\sigma \varepsilon l}$ milísi from verb $\mu \imath \lambda \dot{\alpha} \omega$ miláo 'I speak' in $\theta \alpha \varepsilon^{\chi} \chi \omega \mu \nu \lambda \dot{\eta} \sigma \varepsilon l$ tha ékho ghrápsi "I will have spoken" (cf. Joseph 1983: 69f.). Both forms, which are utterly productive in the colloquial language, do not serve as means of predicate complementation.

${ }^{2}$ Cf. Sitaridou 2014.

${ }^{3}$ Cf. Rohlfs 1960.
} 
of a predicate expressing knowledge is introduced by the CM hópōs whereas the Classical language would use an infinitive instead in this case:

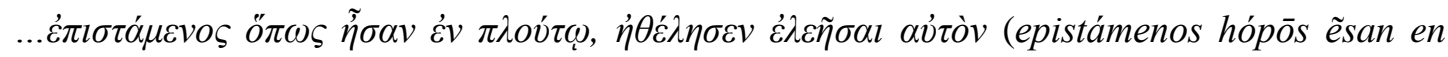
ploútōi èthélēsen eleẽsai autòn: being.aware-how-were.3PL-in-wealth, (he).wantedhelp.AOR.INF. him), “...being aware of the fact that they were wealthy, he wanted to assist him".

This sort of cases is frequent and shows that even in a time in which infinitive was still in use, dependent clauses have been gradually preferred. So, in the texts of the $15^{\text {th }} \mathrm{c}$. onwards, infinitive is just a relic which means that EMG does not differ from SMG in that complementation system is characterized by finite complement structures and even the CMs that are preponderantly found in SMG are the ones that are basically used in EMG as well. What is different in EMG is the distribution of these complement markers, their semantics as well as the fact that the system had not been standardized as it is the case in SMG.

Complementation in SMG is realized then by means of CMs that introduce finite phrases. The system in standard language is tripartite:

a. The indicative / declarative / realis CMs óti and the slightly more colloquial pos selected by

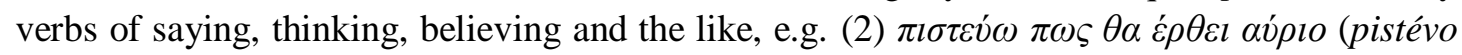
pos tha érthi ávrio: believe.1SG. that FUT come.3SG.+perf. ${ }^{4}$ tomorrow "I believe (s)he will come tomorrow").

b. The irrealis / mood / "subjunctive" particle $n a$ after future-referring verbs of will, effort,

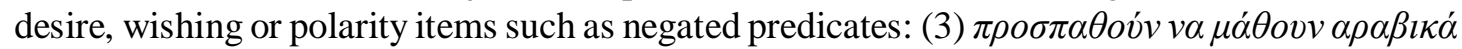
(prospathún na máthun araviká: try M.PRT. learn.+perf. Arabic "they are trying to learn Arabic".

c. The factivity $\mathrm{CM} p u$ occurs after predicates that presuppose the validity of a statement. After certain verbs, e.g. verbs of perception, $p u$ stands in complementary distribution with óti/pos or $n a$ in order to express a. that an event did take place, b. aspectuality (similar to English gerund

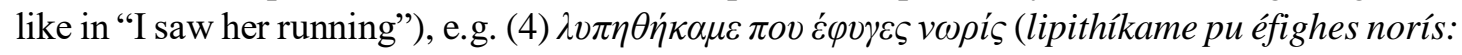
be.sad.1PL.AOR. that leave.2SG.AOR. early) "We were sad that you left early".

Along with these CMs, we could refer to the subordinating particles $\alpha v$ an 'if' / 'whether' and $\mu \eta / \mu \eta$ i $\pi$ s mi/mipos 'lest' which however retain their original adverbial meaning as well, so the clauses that these introduce oscillate between complement and adverbial subordination. For a more detailed account on SMG complementation system, cf. Roussou (2006) and Holton et al. ${ }^{2} 2012$ : 543ff.

\section{Three corpus-based investigations to EMG complementation phenomena}

As already mentioned, the EMG complementation is similar to the SMG, insofar as to show absence of non-finite complements and the systematic usage of the dichotomy between realis and irrealis CMs (oti/pos ${ }^{5}$ vs. na). As we will see in 3.3., in EMG $p u$ is still very rare as a marker of factivity and mainly occurs in its initial meaning as a relativum generale.

\footnotetext{
${ }^{4}$ Verbs in the future tense and the subjunctive mood are marked with $+/$ - perf(ective) aspect values.

${ }^{5}$ In texts of EMG, óti and pos are not used in free variation, at least the way they are in SMG. Dialectic factors would play a role in their distribution, for ex. the Cretan author Morezinos whose work we used in our research barely uses óti $(31 \mathrm{x})$ while pos appears several hundred times (835x along with its original function as an interrogative particle meaning 'how'). According to Jannaris (1897: 413f.), óti was largely
} 
What we briefly examine from a semantic, syntactic and statistical point of view in the following three sections of this chapter are cases, in which EMG differs from SMG. The cases are the following ones:

a. "Pleonastic" usage of the CMs óti, pos and na. In SMG óti and pos are in free distribution and both of them are in complementary distribution with $n a$ or $p u$. This means that these four CMs cannot co-occur in a sentence. On the contrary, as we see in 3.1 in EMG the configurations óti+na, pos+na and óti+pos were possible.

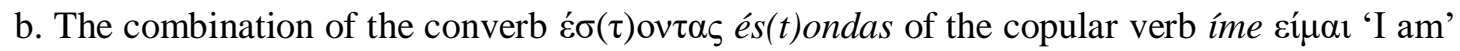
with several CMs. These configurations serve in turn as means of subordination, also conveying several adverbial meanings. This construction is absent in SMG.

c. The rise of $p u$ as a $\mathrm{CM}$ of factivity. As it is suggested, a meticulous view on the texts reveals that it is exactly during the EMG period that this usage of $p u$ emerges.

\subsection{Case 1: "Pleonastic" complement markers in Early Modern Greek (16th c.)}

In our EMG Corpus there are numerous attestations of the configurations ót $i+n a, p o s+n a$ and otitpos. According to the prescriptive MG Grammar these combinations are all ungrammatical in SMG. Although this is basically true, as we will see there are nevertheless some cases in today's language that speakers may utter the combination óti+na. Although this usage is rarely written down, it exists and can be traced in certain colloquial texts especially on Internet posts. On the other hand, the óti+pos configuration sounds "more" ungrammatical and unacceptable to a speaker of MG. This is expected, given that syntactically the two elements are in free variation and thus they both occur in the same "syntactic slot", while na appears in a structural position closer connected with the finite verb ${ }^{6}$.

While in SMG these combinations then are either totally ungrammatical or extremely rare, in EMG they are attested in a certain frequency. In our Corpus we have the following distribution:

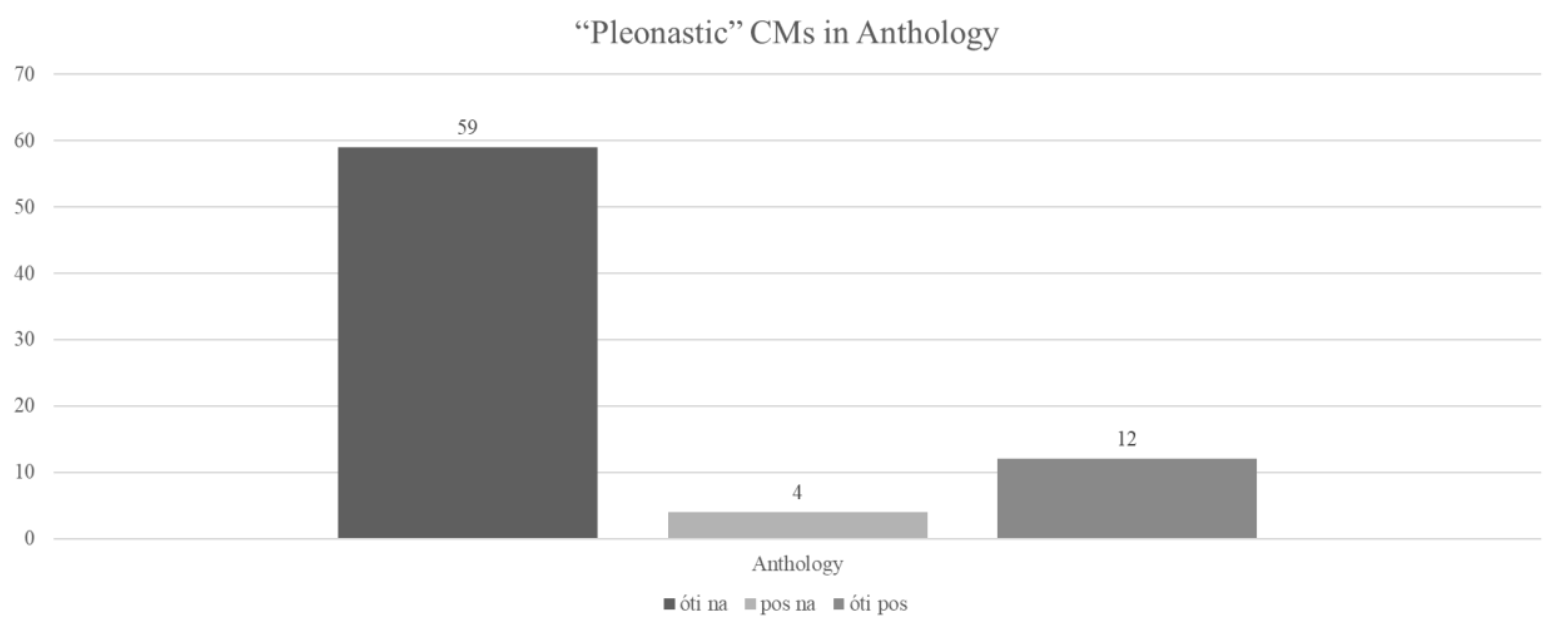

Table 1: "Pleonastic" complement markers in Anthology

displaced by pos, at least in colloquial usage, however ót $i$ was reintroduced in the language due to the linguistics conservatism of many authors. This seems to be true, at least for many MG dialects, although further investigation is needed on this topic.

${ }^{6}$ In terms of Generative Grammar, óti and pos are the heads of a Complementizer Phrase (CP), whereas $n a$ could be analyzed as the head of a Functional Phrase (FP) above the Verb Phrase (in this case some approaches label the FP hosting $n a$ as a "Mood Phrase"). Cf. Sampanis 2012. 
In table 1 Distribution in Anthology's texts: óti $+n a$ : 59x; pos $+n a: 4 \mathrm{x}$; óti + pos: $12 \mathrm{x}$. Obviously, óti $+n a$ is the preponderant "pleonastic" structure. However, this distribution is not similar in all texts of the Corpus. If we combine the text collection of Anthology with Kartanos' and Morezinos' texts (Table 2), we observe that in Morezinos the óti $+n a$ configuration is absent. The exact numbers are the following: In Kartanos: ót $+n a: 283 \mathrm{x}$; pos $+n a: 4 \mathrm{x} ;$ ót $t+$ pos: 20x, Morezinos óti $+n a: 0 \mathrm{x} ;$ pos $+n a: 14 \mathrm{x}$; óti + pos: 9x respectively.

"Pleonastic" CMs in Anthology, Kartanos and Morezinos

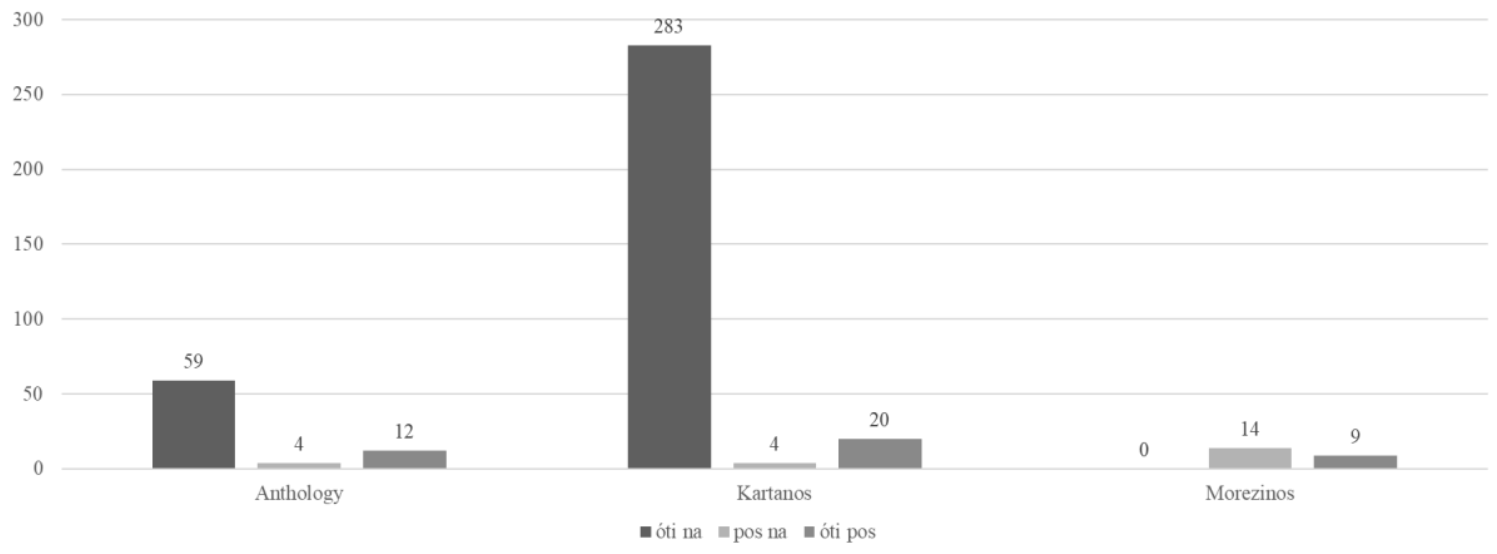

Table 2: "Pleonastic" complement markers in three texts of the Corpus.

These findings confirm the impression that pos was the main declarative CM in several MG dialects and óti was an archaic element, probably obsolete in colloquial registers. More research on this field concerning the óti vs. pos usage at that period should be done, given that the "survival" and revival of ot $t$ in SMG is apparently associated with linguistic conservatism. This issue has still not been clarified by the researchers working on the diachrony of sentential complementation in Greek.

Now, in turn, we can have a closer look at the distribution and semantics of the óti $+n a$. These topics have been discussed in detail in Karantzola and Sampanis $2016^{7}$ and will be presented here in a nutshell.

Firstly, the ót $+n a$ combination could also introduce an adverbial subordinated clause, namely a final one. This is illustrated in the distribution of oti $+n a$ in two texts of the Corpus with respect to the parameter Complement Clauses vs Adverbial Clauses (Table $3 \& 4$ respectively):

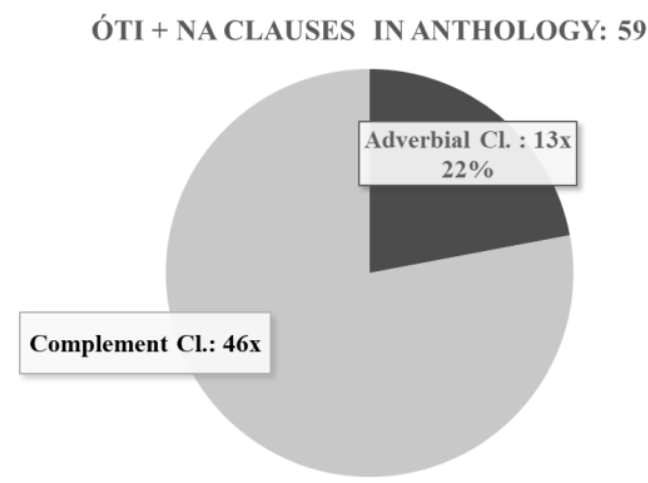

Table 3: Distribution of the ót + na clauses (Complement Clauses vs Adverbial Clauses) in Anthology.

\footnotetext{
${ }^{7}$ Available on: https://www.academia.edu/30158152/On_the_Pleonastic_Usage_of_Complement_Markers_in_Early_Modern_Gr eek, retrieved 20.05.2018
} 


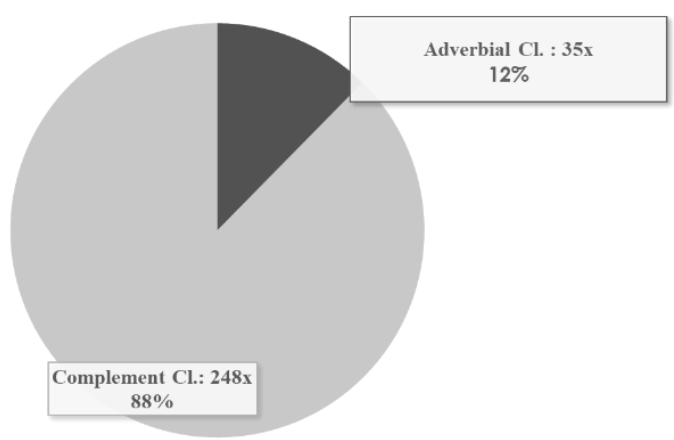

Table 4: Distribution of the óti $+n a$ clauses (Complement Clauses vs Adverbial Clauses) in Kartanos

The question that arose after the examination of the distribution of the óti $+n a$ clauses is if their distribution is idiosyncratic or if they occur in accordance with a pattern. Karantzola and Sampanis (ib.) notice that óti $+n a$ clauses are chiefly selected by particular categories of predicates, mainly from commissive, directive, causative, desiderative and modal ones. The rationale behind this usage is then the expression of directionality, in which a $\mathrm{X}$ person says or orders a Y person to do something, therefore these constructions are largely connected with subject obviation and embedded imperatives or subjunctives in indirect speech. Consider (5):

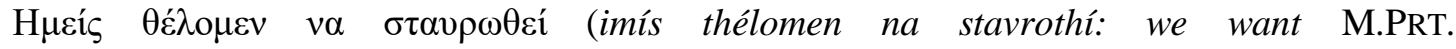
be.crucified.3SG.+perf. "We want him to be crucified", Kartanos, Testament 272). Also

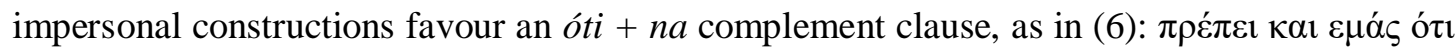

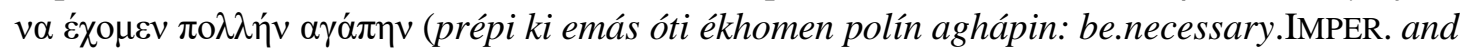
us that M.PRT. have.1PL.PRES. much love) "We should also have much love..." (Anthology: 49). In this case directionality emerges not from a person addressing another one but because of the deontic modality of the impersonal predicate which is associated with directionality ("It is necessary for Y to do sth"), therefore óti $+n a$ is similarly an option in these cases.

Interestingly, the investigation of these structures, which had been largely understudied up to know, enabled a contrastive comparison with similar phenomena in other languages. Sampanis, Karantzola and Fykias (2016) ${ }^{8}$ discuss cases in Albanian in which a complement subordinator appears jointly with the Mood Particle, as it is the case in Greek as well, cf. (7): Çfarë doni që të bëj për ju? (what want.2PL.PRES. that M.PRT. do.1Sg. for you) "What do you want me to do for you?". Also in Farsi, the parallel occurrence of a CM and a Mood Particle can be found (8): mikhâham (ke) (to) barâyaš yek e-mail beferesti (want.1SG. (that) (you) toher one e-mail M.Prt. ${ }^{9}+$ send.2SG.) "I want you to send her an e-mail".

As discussed above, in SMG the óti + na clauses are considered ungrammatical, e.g. example (9) would be characterized as unacceptable by almost all MG native speakers: * $\pi \rho \varepsilon ́ \pi \varepsilon \iota$ ótı va $\delta \iota \alpha \beta \alpha ́ \sigma \omega$ (prépi óti na diaváso: be.necessary.IMPER. that M.PRT. read.1SG., +perf.) "I have to read".

Still, there seem to be some cases in which acceptability of these constructions increases,

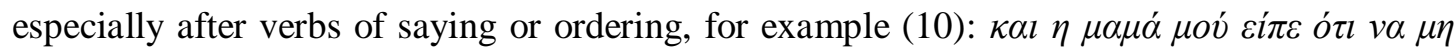

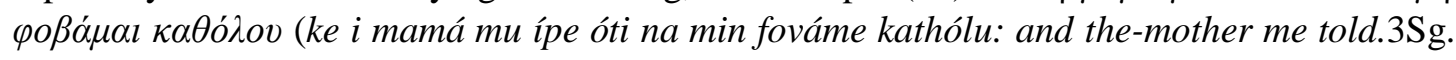

\footnotetext{
${ }^{8}$ Accessible on: https://www.academia.edu/28321330/Complementiser_plus_mood_particle_constructions_in_Modern_Albanian_ and_Early_Modern_Greek_A_contrastive_approach, retrieved 20.05.2018.

${ }_{9}$ The mood particle here is the prefix $b e$-. Thanks are due to Feryal Honarmand, native speaker and language instructor of Farsi, for the example.
} 
that M.PRT. not be.afraid.1SG.-PERF. at-all.) "My mum told me I should not be afraid at all". Sentences of that kind are attested in Internet texts and in a few cases the structure found its

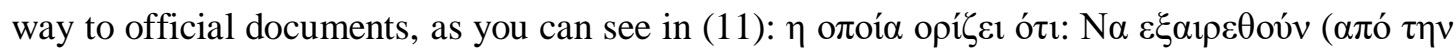

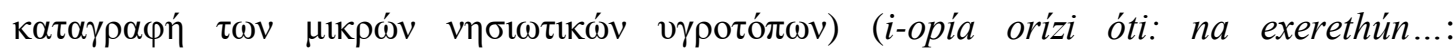
which.NOM.SG.F. ordain.3SG. M.PRT. be excluded.3PL.+perf.) "...(the decision) which sets out that: (the listing of small island lakes) should be excluded....".

The case in (11) emerges as a result of two stylistic banalities of the bureaucratic language: a. the (slightly archaic) verb orizi should select óti, while what follows is an embedded subjunctive serving as a speech act of ordering. In this usage, óti serves as sort of "quotation marks" losing its strictly realis reading. This is the function we examined above in the Albanian example (7), which is also reminiscent of how the predecessor of óti $(<$ hóti) could introduce direct speech in Koine Greek (the so-called hoti-recitativum, cf. Blass, Debrunner \& Funk 1961 $\S 470$, and Levinsohn 1999).

Summing up this section, we observed that the EMG corpus allows us to gain insights into phenomena that are revealing not only for the history of the language but also for the syntactic and semantic properties of the elements we discussed as well as for the understanding of analogous phenomena in either languages.

\subsection{Case 2: The copular verb's converb és(t)ondas + complement markers}

The second case we are going to examine pertains to a construction that is not attested in SMG

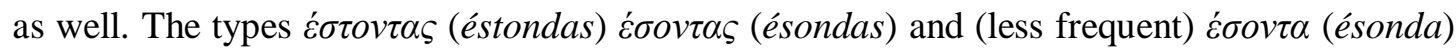
or $\varepsilon \sigma o ́ v \tau \alpha$ (esónda) are associated with the MG non-finite verbal category of gerunds (cf. e.g. Holton et al. ${ }^{2} 2012$ : 306f.) or adverbial participles. The designation we will select herein is the term 'converb' in the sense of Haspelmath 1995. MG converbs have been evolved out of the Ancient Greek participles of present active verbs cf. Manolessou 2005a.

The afore-mentioned types derive from the verb símal ime ' $\mathrm{I}$ am' ${ }^{10}$ and can be translated as 'being'. The ordinary "process" of deriving converbs in SMG is by combining the non-

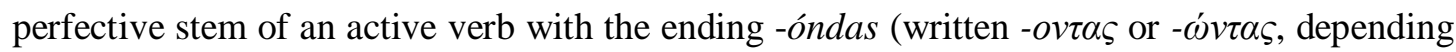

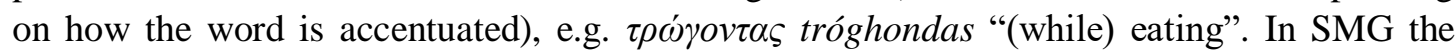
converb of the copular verb ime is óvtas óndas, a form that has equally been developed by the AG participle.

Although és(t)ondas belongs to the category of converbs, it barely occurs independently of a CM. In our Corpus ${ }^{11}$, és $(t)$ ondas is followed by the Mood Particle na, the Declarative Subordinator óti or pos, the Local/ Relative pronoun opú as well as the Coordinator ke 'and' which also encodes subordinating meanings in certain cases. Joint usage of these CMs is also possible after the copular converb, as we will see below.

The combination of és(t)ondas + CMs expresses a number of adverbial meanings, such as temporal (12), causal (13) and in some cases adversative/ concessive (14):

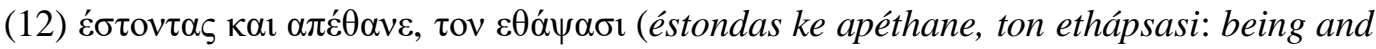
die.3SG.AOR., him bury.3PL.) "When he died, they buried him" (Chartofylax: Jew.Ant. 119)

\footnotetext{
${ }^{10}$ MG has no infinitive so verb types are given in the first person singular.

${ }^{11}$ In this section, we have also included an EMG rendition of texts of Titus Flavius Josephus, cf. Chalvatzidaki 2013.
} 


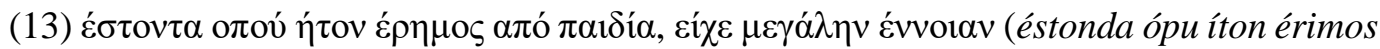
apó pedhía, íkhe meghálin énian: being that(<where)be.3SG.IMP. alone from children, have.3SG.IMP. great concern) "Being deprived of children, he had great distress." (Anth.: 82)

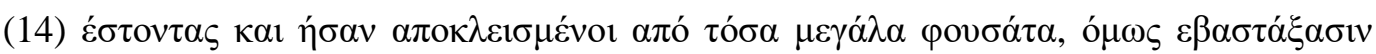
(éstonda ke isan apoklisméni apó tósa meghála fusáta, ómos evastáksasin: being and be.3PL.IMP. surrounded.PRC.NOM.PL.M from so big troops, but endure.3PL.AOR.) "Although they were surrounded by so strong troops, they kept their positions" (Pol.:35).

However, in most cases the constructions' meaning oscillates between causality and temporality. In terms of Cognitive Grammar, the és(t)ondas + Complement Marker configuration functions as a setting within which the described events of the clause take place, as adverbial expressions with scope on an entire clause $\mathrm{do}^{12}$. What is more, in the various configurations with a CM, és(t)ondas drops its lexical meaning and tends to become more grammaticalized. This is indicated not only semantically but also by the fact that the combination of the copular converb and the CM can be followed itself by a finite copular verb as in (15) below. The finite copular verb then performs the lexical semantic function (as part of the predicate) in this case, while és(t)ondas tends to form a complex subordinator with the CM.

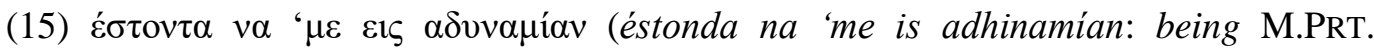
be.1SG.PRES. in weakness) "Being in weakness..." (Grigoropoulos: doc. 140).

Concerning now the distribution of the CMs after és(t)ondas, it is uncertain whether choosing one $\mathrm{CM}$ over another after the copular converb played a distinctive role in the semantic interpretation of the whole configuration. What appears to be significant in selecting a $\mathrm{CM}$ is the stylistic or dialectic properties of each text and author. As it is obvious in the tables below for example, certain authors employ particular és(t)ondas + CM constructions while within the whole EMG Corpus there is no uniformity of how the construction is used. For example, the Cretan Morezinos exclusively combines és(t)ondas with $k e+n a$, while Chartofylax preference lies in és(t)ondas $+k e$, in a way that outnumbers any other construction in the most conspicuous way ${ }^{13}$. The statistics suggest that there were many varieties of this construction which did not necessarily differ from each other in terms of semantics.

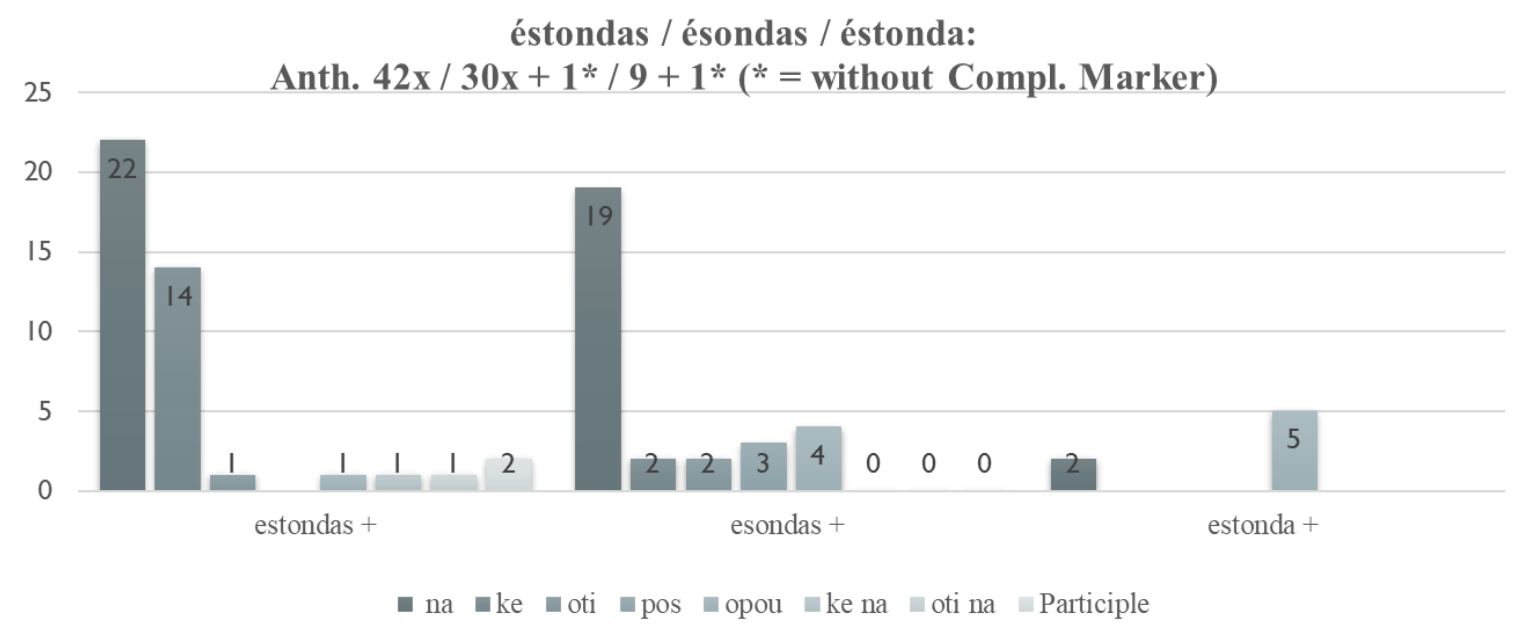

Table 5: és(t)ondas + CMs in Anthology

\footnotetext{
${ }^{12}$ Cf. e.g. Langacker 2008: 358.

${ }^{13}$ For further information on the topic, cf. https://www.academia.edu/36499069/On_the_\%CE\%AD_\%CF\%83_\%CF\%84\%CE\%BF\%CE\%BD\%CF\%84\%C E\%B1\%CF\%82_Syntactic_Constructions_and_Semantic_Functions_in_Early_Modern_Greek.
} 


\section{Distribution of estondas in Corfiot Kartanos and Cretan Morezinos}

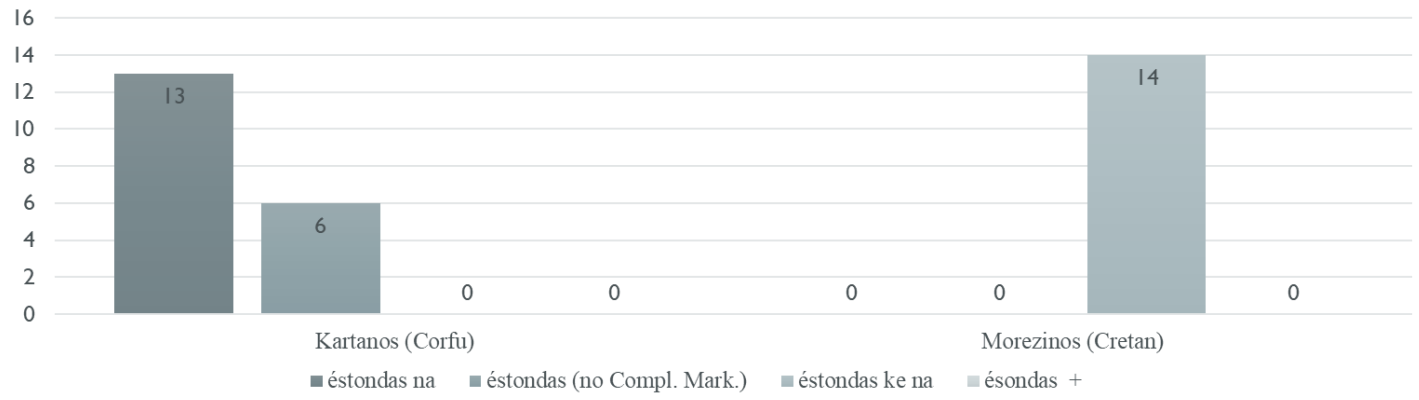

Table 6: és(t)ondas + CMs in Kartanos and Morezinos

éstondas / ésondas Papaioannou: 22x / 1x

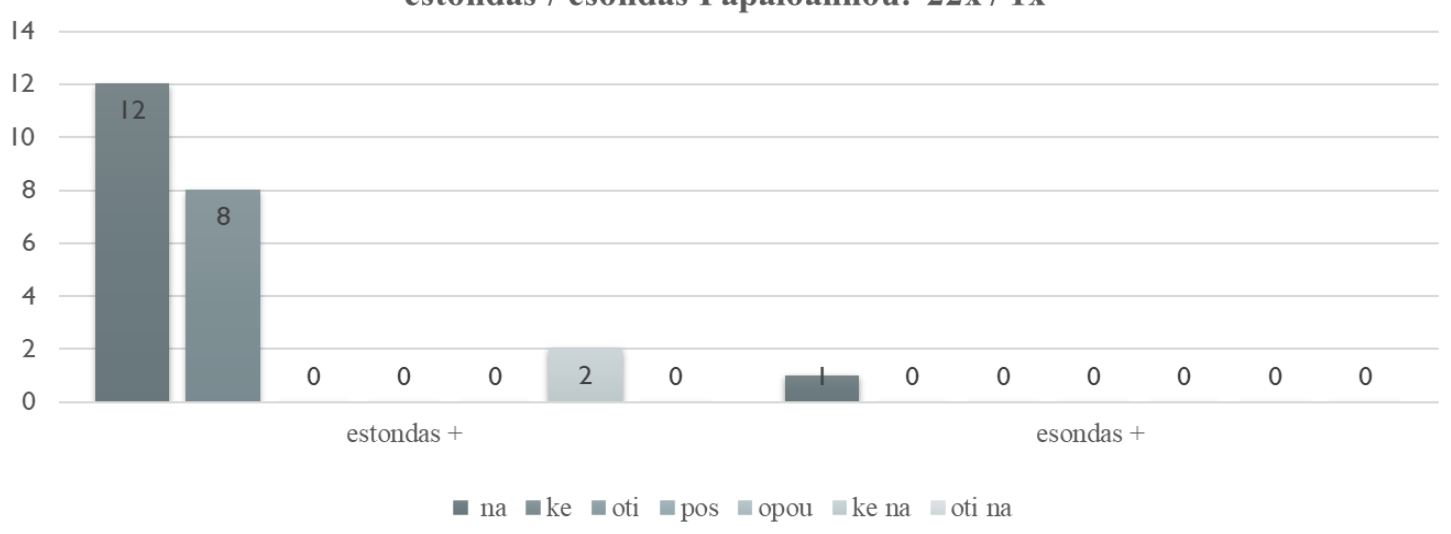

Table 7: és(t)ondas + CMs in Papaioannou 2016

Distribution of estondas in Chartofylax (X625)

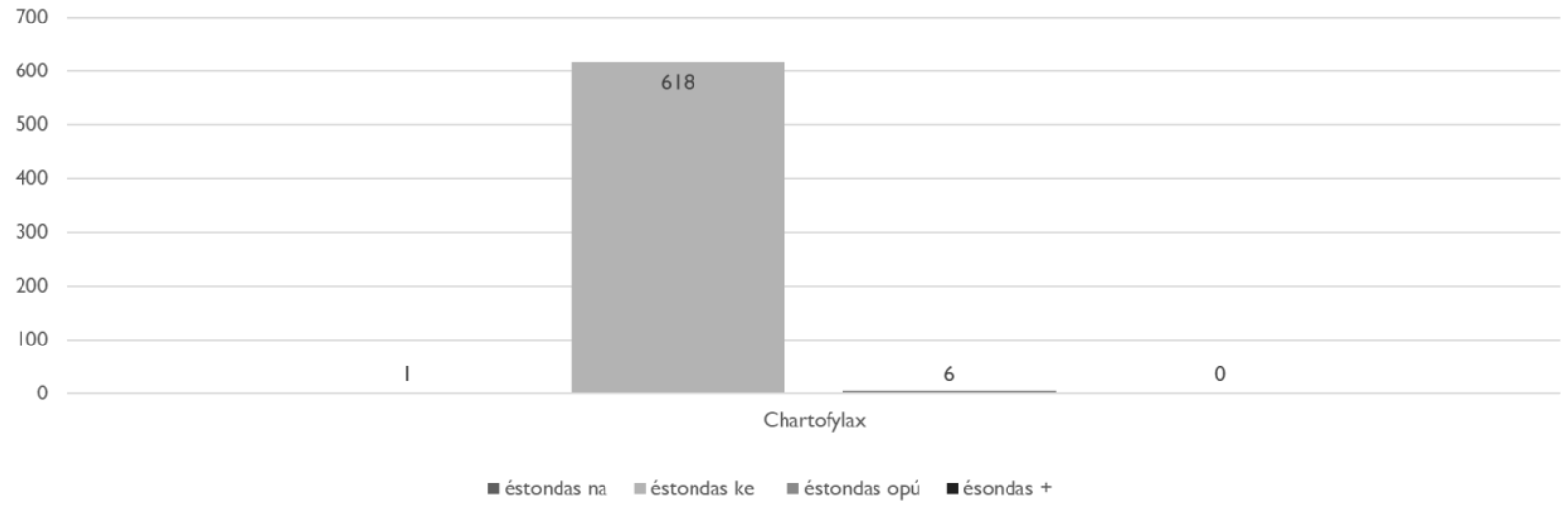

Table 8: és(t)ondas + CMs in Manouel Chartofylax (mid $16^{\text {th }} \mathrm{c}$.)

Concerning now the etymology of the és(t)ondas forms, it has been suggested that these types stem from the AG imperative $\tilde{\varepsilon} \sigma \tau \omega$ éstō (3.Sg. Pres.) with the corresponding converbal ending. Nevertheless, such an interpretation is rather vague since no other MG converb is formed on the morphological basis of an imperative. We suggest, following alternative 
etymological attempts ${ }^{14}$, that és(t)ondas emerged under the influence of the Italian essendo che, nowadays a rather archaic construction in this language ${ }^{15}$. The association of és(t)ondas $+\mathrm{CM}$ with essendo che is corroborated by the fact that translations from Italian notary texts into Greek render essendo che of the original text as és(t)ondas $+\mathrm{CM}^{16}$. This etymology proposal is reasonable and provides an explanation about the morphological peculiarity of és(t)ondas. While the copular verb converb in SMG is óndas which is a regular form, és(t)ondas has emerged under the influence of essendo, and this how the stem of the converb is explained: a form with an initial $e$ was preferred in order to provide a degree of similar iconicity to the Italian form. What is more, the adjusted subordinator, che which can select indicative or subjunctive in Italian, may have led to the connection of the Greek converb with both ke and na initially (and consequently with the rest of CMs). Although $k e$ is a coordinator, it sounded like the Italian che and since this element can also be found as a subordinator, it could occur as a CM. In turn, $n a$ or óti may have been occur in more precise translations.

In SMG the construction is completely unknown, although it is actually frequent in certain texts of EMG, as the research through the Corpus affirms. A factor for its becoming obsolete may have been the great variety of types and constructions. The absence of a more standardized usage may have led to a certain uncertainty concerning what is right or wrong. Nevertheless, for the time being this is a working hypothesis. Moreover, a more diachronic approach is needed in order to understand the rise and fall of és $(t)$ ondas $+\mathrm{CM}$. Both research questions are currently being investigated by the authors of this paper.

\subsection{The rise of the factive complementiser $p u$}

As we mentioned in chapter $2, \mathrm{MG}$ expresses factivity through clauses introduced by the CM $p u$. The $p u$ element is selected by verbs expressing an emotional state (emotives) like the example we saw in (4) or by verbs of perception. In the latter case, $p u$-clauses resemble the

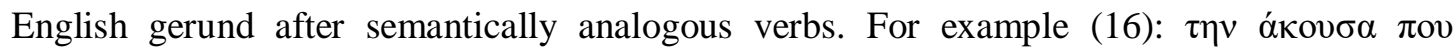

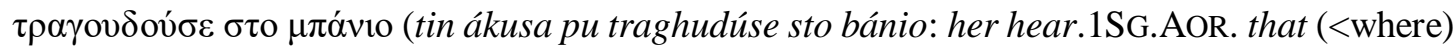
sing.3SG.IMP. in bathroom) "I heard her singing in the bathroom".

The factive complementiser derives from the AG locative relative ö $\pi$ ov hópu 'where' and the interrogative $\pi$ ov $p \hat{u}$ 'where?'. Through a shift of the accent, and the parallel loss of the initial aspiration, hópu became opú and then $p u$, probably under the influence of the monosyllabic interrogative form. In EMG Corpus, both opú and $p u$ introduce relative clauses, although opú is far more frequent. In SMG $p u$ is the only form that occurs as relativum generale,

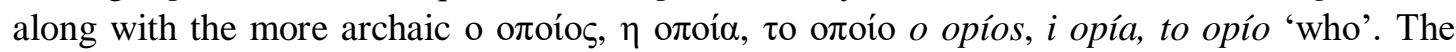
latter elements are declinable whereas $p u$ has no nominal declination and can replace $o$ opíos etc. in all contexts except when the relative pronouns refer to a genitive ("whose").

Regarding the rise of the factivity readings out of relative $p u$ in SMG, Nicholas (1998: $460)$ indicates the following semantic "paths":

a. After perception predicates relativisation and object rising is involved: So, a clause like (16)

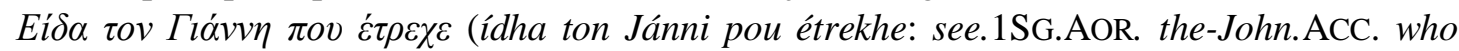

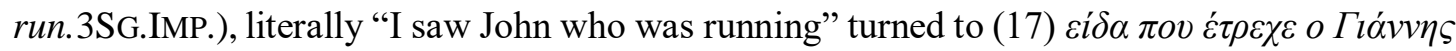
(ídha pou étrekhe o Jánnis: see.1SG.AOR. who run.3SG.IMP. the-John.NoM.) "I saw John running". However, it should be considered that in SMG both (16) and (17) have a factive

\footnotetext{
${ }^{14}$ Cretan Chronicles 28 -29: 1988.

${ }^{15} \mathrm{Cf}$. http://dizionari.repubblica.it/Italiano/E/essendoche.php, retrieved 26/05/2018.

${ }^{16} \mathrm{http} / / /$ www.oocities.org/marin_serban/papakosta3.html, retrieved 26/05/2018.
} 
reading, since in (16) it would be awkward to replace $p u$ with o opíos. This implies that even in this case, $p u$ is a factive $\mathrm{CM}$ rather than a relative one.

b. After emotives, Nicholas (ib.) suggests that "the pu-complement is causal in nature, and

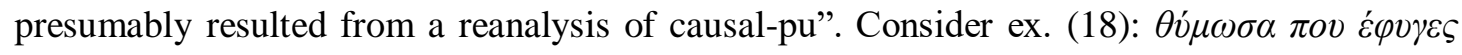
(thímosa pu éfighes: get-angry.1SG.AOR. that left.2SG.) "I got mad that you left" < "I got angry because you left".

c. After the verb $\theta v \mu \alpha \dot{\alpha} \mu \alpha$ thimáme 'I remember' Nicholas (ib.) sees a temporal reading. This

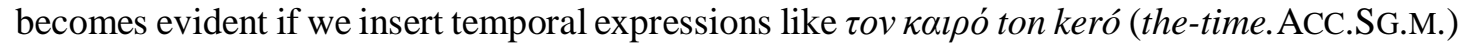

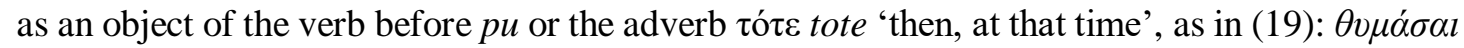

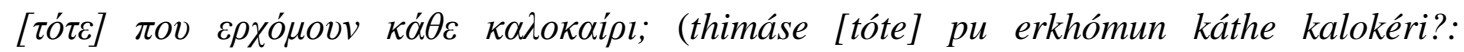
remember.2SG.PRES. then that come.1SG.IMP. every summer). "Do you remember (the time) when I used to come every single summer?"

Thus, we observe that the factivity of $p u$ did not emerge independently of other semantic categories. What is still not absolutely clear is when exactly in the diachrony of Greek the relative $p u$ started functioning as a factive $\mathrm{CM}$.

As already mentioned, in our Corpus, both opú and $p u$ are predominantly CMs that introduce relative clauses. Still, after a meticulous examination of numerous clauses introduced by the two CMs, it is feasible to locate a few cases in which opú and $p u$ can be described as

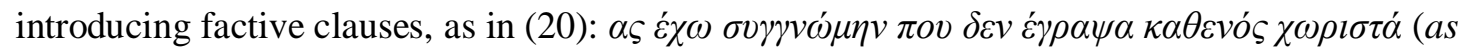
ékho sighnómin pu dhen éghrapsa kathenós khoristá: let have.1SG.PRES. excuse that not write.1SG.AOR. each separately) "Let me be pardoned for not having written to each one of you separately" (Anthology: 249).

As table 9 reveals, these cases in two of the texts of our Corpus, the Anthology and Papaioannou's collection of prose texts, are extremely rare. However, cases like in (20) indisputably involve factivity. On these grounds then we could put forward that it is in EMG that $p u$ gradually emerges as a factive CM. This constitutes then a tentative terminus post quem for our investigation. Although further research on the topic is needed, the scarcity of the examples as well as their very occurrence is suggestive that the phenomenon was about to rise in the language.

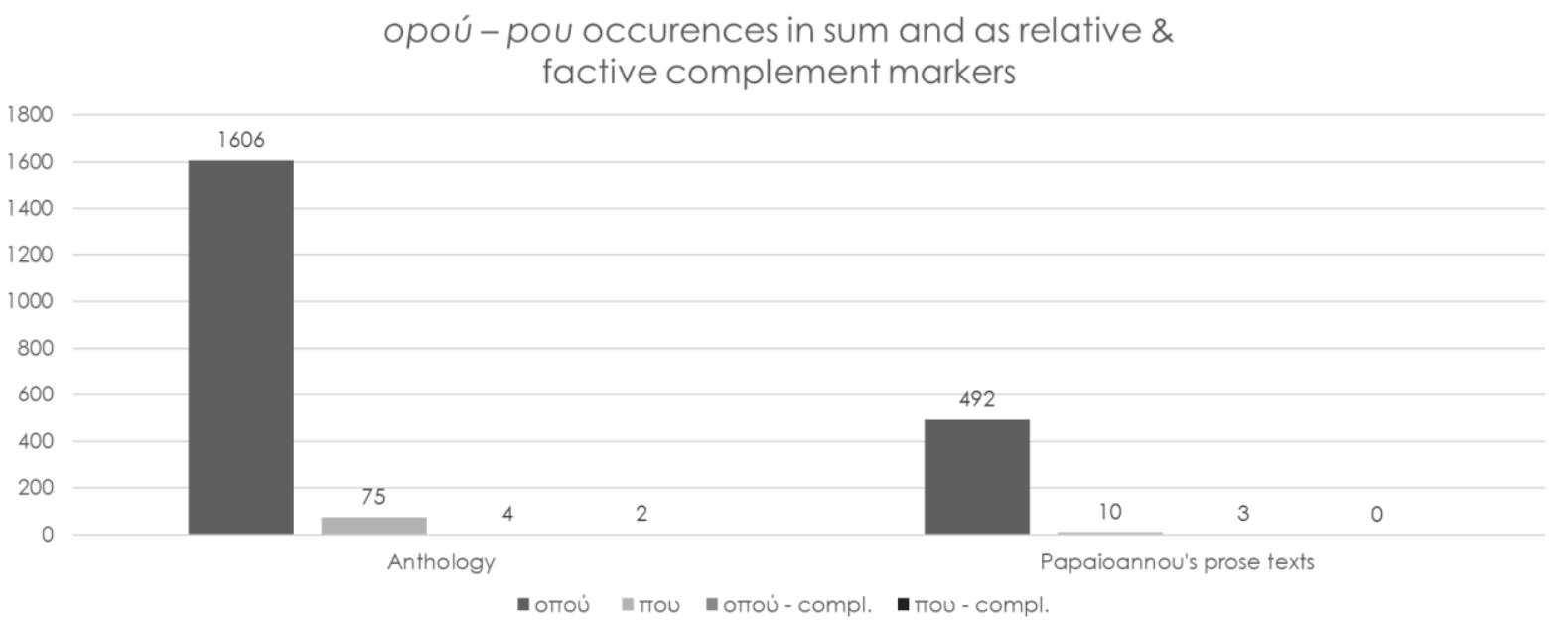

Table 9: opú and $p u$ as relative and factive CMs in Anthology and Papaioannou 


\section{Concluding remarks}

In this paper we examined three cases concerning the syntactic structure and the semantics of Early Modern Greek Complement Markers. All three cases have been up to now virtually unnoticed. In fact, it was through the investigation of our Corpus that it is possible to gain subtler insights about their function and their distribution. Additionally, the fact that two of the constructions could not find their way to SMG raises the question of how elements and constructions rise or become obsolete in the diachrony of a language. Statistical approaches and observation of less frequent cases could shed light on this topic as well.

\section{Bibliography}

Biber, Douglas - Conrad, Susan and Randi Reppen. 1998. Corpus Linguistics: Investigating Language Structure and Use. Cambridge: Cambridge University Press.

Blass, Friedrich, Albert Debrunner and Robert W. Funk. 1961. A Greek Grammar of the New Testament. Chicago: University of Chicago Press.

Chalvatzidaki, M. 2013. "Colloquial Rendition of Jewish Antiquities and the Jewish Wars of Flavius Josephus $\left(1^{\text {st }}\right.$ c. A.D. $)$ composed by Manouel Chartofylax $\left(16^{\text {th }}\right.$ c.): Text Edition, Philological and Linguistic commentary.” Unpubl. Dissertation, University of the Aegean.

Haspelmath, Martin. 1995. "The converb as a cross-linguistically valid category". In Haspelmath \& König 1995, 1-56.

Haspelmath, Martin and Ekkehard König (eds.). 1995. Converbs in Cross-Linguistic Perspective. Structure and Meaning of Adverbial Verb Forms: Adverbial Participles, Gerunds. Berlin / New York: Mouton de Gruyter.

Holton, David, Peter Mackridge and Irene Philippaki-Warburton. 2012. Greek: A Comprehensive Grammar. 2nd ed. revised by Vassilios Spyropoulos. London and New York: Routledge.

Horrocks, Geoffrey. ${ }^{2} 2010$. Greek: A History of the Language and its Speakers. 2nd ed. WileyBlackwell.

Jannaris, Antonios N. 1897: An historical Greek grammar, chiefly of the Attic dialect. Hildesheim: Georg Olms. Reprint 1987.

Joseph, Brian D. 1983. The Synchrony and Diachrony of the Balkan Infinitive. A Study in Areal, General, and Historical Linguistics. Cambridge: Cambridge University Press.

Kakoulidi-Panou, Eleni (ed.). 2000. Ioannikios Kartanos. Palaia te kai Nea Diathiki (Venice 1536) [in Greek]. Thessaloniki: Centre for Greek Language.

Kakoulidi-Panou, Eleni, Eleni Karantzola and Maria Chalvatzidaki (eds). 2007. Ioannis Morezinos. Klini Solomontos (1599) [in Greek]. Iraklio: Etairia Kritikon Istorikon Meleton.

Kakoulidi-Panou, Eleni, Eleni Karantzola and Katerina Tiktopoulou (in press). Demotic Prose Texts of the 16th c. [in Greek]. Thessaloniki and Athens: Centre for Greek Language and MIET.

Karantzola, Eleni and Konstantinos Sampanis. 2016. "On the "pleonastic" usage of complement markers in Early Modern Greek". Journal of Greek Linguistics Vol. 16, Issue 2, $202-231$. 
Kroch, Anthony. 1989. "Reflexes of grammar in patterns of language change". Language Variation and Change 1, 199-244.

Langacker, Ronald W. 2008. Cognitive Grammar. A Basic Introduction. Oxford: Oxford University Press.

Levinsohn, Stephen H. 1999. “"O device?" In Work Papers of the Summer Institute of Linguistics, University of North Dakota Session 1999 Volume 43. Online url: http://www.und.edu/dept/ linguistics/wp/1999Levinsohn.PDF

Manolessou, Io. 2005. "From participles to gerunds". In Advances in Greek Generative Syntax, Melita Stavrou and Arhonto Terzi (eds.) 241-284. Amsterdam and Philadelphia: John Benjamins.

Nicholas, Nick. 1998. The story of pu. The grammaticalisation in space and time of a Modern Greek complementiser. Unpubl. Diss.

Papaioannou, Anastassios. 2016. Prose texts in vernacular Greek, of writers of the 16th and 17th c., according to autographs manuscripts [in Greek]. Unpublished $\mathrm{PhD}$ thesis, University of the Aegean, Rhodes.

Roussou, Anna. 2006. Complementizers [in Greek]. Athens: Patakis.

Rohlfs, Gerhard. 1960. „Zwischen Koiné und Neugriechisch (Zur Herkunft der italogriechischen Dialekte)“. In Glotta 38: 89-106.

Sampanis, Konstantinos. 2012. "The Modern Greek subjunctive mood and its semantic features". In Current Trends in Greek Linguistics, Georgia Fragaki, Thanasis Georgakopoulos and Charalambos Themistocleous (eds), 66-91. Cambridge Scholars Publishing.

Sampanis, Konstantinos, Eleni Karantzola and Ioannis Fykias. 2016. "Complementiser plus mood particle constructions in Modern Albanian and Early Modern Greek: A contrastive approach." Oral presentation presented at SLE 2016: 49th Annual Meeting of the Societas Linguistica Europaea, 31.08 - 3.09. 2016, University of Naples Federico II, Workshop: The rise of complementizers and their relation to subjunctive mood and (ir)realis distinctions.

Sitaridou, I. 2014. "The Romeyka Infinitive: Continuity, Contact and Change in the Hellenic varieties of Pontus". Diachronica 31.1. pp. 23 -73.

Tonnet, Henri. ${ }^{32011 . ~ H i s t o i r e ~ d u ~ g r e c ~ m o d e r n e: ~ L a ~ f o r m a t i o n ~ d ' u n e ~ l a n g u e . ~ T r o i s i e ̀ m e ~ e ́ d . ~}$ Paris: L'Asiathèque. 